\title{
Tryptophan Measurement
}

National Cancer Institute

\section{Source}

National Cancer Institute. Tryptophan Measurement. NCI Thesaurus. Code C154739.

The determination of the amount of tryptophan present in a sample. 